\title{
ENCAROÇADA DE ESTRELAS: ALGUNS POEMAS DE PAULO HENRIQUES BRITTO E A TRANSIÇÃO DEMOCRÁTICA
}

Roberto Zular

Universidade de São Paulo (USP), São Paulo,SP - Brasil.<rzular@usp.br>

http://dx.doi.org/10.1590/ 0102-6445015-037/96

Manhã engole essa noite Encaroçada de estrelas (PHB, MACAU, 2003, P. 29)

\section{Transição?}

Há um emaranhado confuso na experiência recente de nossa transição democrática que, a princípio, impediria qualquer possibilidade de escrever sobre o assunto. Contudo, essa mesma confusão - atrelada ao modo como o autoritarismo e os próprios militares conduziram essa passagem parece ter-se tornado um dos aspectos mais relevantes a ser pensado. Passadas mais de duas décadas, ainda estamos "em transição", como se isso justificasse o convívio cotidiano com traços ditatoriais e com a impossibilidade de discutir o solo mesmo no qual se baseia nossa democracia.

O estudo dessa transição ganha relevo na medida em que autores como Anthony Pereira (2010) defendem que o controle sobre a transição e também a natureza das democracias após a transição foram extremamente afetadas pelos diferentes contornos institucionais dos regimes militares 
do Brasil e do Cone Sul. O que quer dizer que ditaduras como a brasileira, fortemente legalistas, puderam controlar melhor o processo de democratização e de achar soluções de continuidade mais evidentes, como a manutenção do aparelho repressivo. Pereira destaca ainda que muitas decisões tomadas durante o regime não foram repudiadas e mesmo leis totalmente arbitrárias continuaram em vigor.

Como corolário dessa intricada e frágil passagem entre autoritarismo e democracia espraiou-se por todos os lados e na literatura não poderia ser diferente - uma política pautada em estruturas consensuais, ou melhor, na formação e manutenção do consenso como pauta primeira da política e que tem a forja do plano real, no nível econômico, como seu método mais explícito.

Tudo parece indicar para a perpetuação de uma relação com o passado autoritário que não se completa, mas não porque ela advenha de um processo de ressignificação 16 ou de um luto contínuo (como uma "democracia por vir"), mas exatamente porque ela se deu de maneira autoritária e de um modo rápido demais. A velocidade, aliás, parece ser aquilo que foi preciso para suturar o viés autoritário.

Basta ver o modo como a construção das bases legais dessa longa transição democrática foi construída às pressas: um "golpe" transformou o Congresso em Assembleia Nacional Constituinte, 24 senadores não foram eleitos, cinco artigos da Constituição sequer foram votados e, eis um exemplo evidente do que trataremos aqui, o atual vice-presidente da República se gaba de ter acrescentado sozinho, no final da comissão de redação, o termo "harmônicos" do artigo $2^{\circ}$ da Carta Magna ${ }^{1}$.

Dentro desse quadro, percebe-se que a formação de consenso se deu por uma forma muito peculiar de relação

\footnotetext{
1 Constituição da República Federativa do Brasil de 1988. Art. 2: "São Poderes da União, independentes e harmônicos entre si, o Legislativo, o Executivo e o Judiciário". O conchavo contido nesse "harmônico" não deixa de ser significativo.
} 
com a lei, na qual o legal e o ilegal operam juntos em um mesmo funcionamento. A própria velocidade da formação desse aparato legal deixa um infinito número de rastros irresolúveis, que acirram a possibilidade de se estar, ao mesmo tempo, dentro e fora da lei.

Se um dos traços do golpe militar, como de todos regimes autoritários, foi separar corpo e lei ${ }^{2}$, em um processo de triagem que define de modo violento a quem a lei se aplica, o novo consenso parece operar por um modo de relação com a lei, com a regra e com a própria subjetividade, como uma espécie de encenação pautada em dois discursos concomitantes: o que aceita e formula a regra e o que a relativiza por se tratar de um mero teatro que não é feito exatamente para ser seguido, ou melhor, para ser seguido sem que se acredite nele; o que permite a todo momento divergir de si mesmo, da própria regra e dos papéis institucionais que ela cria.

Não se trata de dizer aqui que tudo continuou igual, nem de diminuir a importância da função negativa da democracia como regime que se opõe à opressão, à repressão; muito menos se trata de dizer que estamos diante de um Estado de exceção que se perpetua (essa espécie de banalização do Estado de exceção curiosamente é defendida até por Eros Grau enquanto ministro do Supremo Tribunal Federal ${ }^{3}$ ). Trata-se de um escopo menor, de tentar ver através da poesia a indeterminação

\footnotetext{
2 Essa separação colocava a arte em um amálgama confuso de contracultura e ditadura, expressão corporal e tortura. É um jogo difícil em que se é obrigado a jogar com as regras do outro. Nesse movimento, o próprio lastro começa a ruir e as palavras aos poucos vão perdendo sua estrutura de organização, apontando para um novo modo de circulação dos discursos quase paralelo à perda do lastro ouro que sustentava o sistema monetário internacional. O Brasil entra na pós-modernidade por essa perda de lastro instaurada entre corpo e linguagem pela violência da ditadura. As palavras cedem à imediatidade e perdem sua possibilidade de mediação, a própria enunciação da lei traz no seu corpo as marcas da violência.

3 Ver sua introdução ao livro de Carl Schmitt, Teologia política (Belo Horizonte, Del Rey, 2006).
} 
que se produz sobre o lugar da política em uma lógica pautada na definição e repartição dos corpos a partir de lugares predefinidos ${ }^{4}$.

Mantivemos nessa ideia de transição uma espécie de fantasia democrática, como se o mecanismo imaginário de sua constituição e a forma burocrática de sua normatização continuassem a ser uma marca constitutiva. No excesso de leis, direitos, princípios, em que rapidamente foram definidos os meios e as partes envolvidas, a luta se trava a partir de então por formas de inclusão. A extensão dos interesses e o debate sobre sua aplicabilidade gerou uma luta para saber não quais são os direitos mas quem tem a possibilidade ou não de fazer valer os direitos que estão no texto constitucional. O que há de mais democrático na Constituição é reconhecer uma pluralidade de pessoas, gêneros, culturas, classes, empresas que estão fora dela, mas, ao mesmo tempo, ficamos diante de um 18 paradoxo, pois, ao reconhecer esses direitos, se produz uma inclusão exclusiva como forma legal e se transfere para outra esfera - da gestão administrativa ${ }^{5}$ - as formas de partilha.

\section{Biodiversidade}

Creio que um poema de Paulo Henriques Britto (PHB) não poderia ser mais significativo no bojo dessas questões. Até por ser um poema que apareceu pela primeira vez em 1998 e que se tornou o poema de abertura do livro Macau, publicado em $2003^{6}$ :

\footnotetext{
4 O que se discute aqui, portanto, não são os direitos - absolutamente necessários -, mas a transformação da política em uma mera gestão de direitos.

5 Esse argumento parte de A era da indeterminação (Oliveira e Rizek, 2007), especialmente o artigo de Chico Alvim: "Política numa era de indeterminação: opacidade e reecantamento".

6 Trataremos neste artigo basicamente dos poemas de abertura dos livros Macau e Tarde (de 2007) e da série "Até segunda ordem" do livro Trovar claro (de 1997).
} 


\section{Biodiversidade}

Há maneiras mais fáceis de se expor ao ridículo, que não requerem prática, oficina, suor. Maneiras mais simpáticas de pagar mico e dizer olha eu aqui, sou único, me amem por favor.

Porém a quem se preste a esse papel esdrúxulo, como há quem não se vexe de ler e decifrar, essas palavras bestas estrebuchando inúteis, cágados com as quatro patas viradas pro ar.

Então essa fala esquisita, aparentemente anárquica, de repente é mais que isso, é uma voz, talvez, do outro lado da linha formigando de estática, dizendo algo mais que testando, testando, um dois três,

câmbio? Quem sabe esses cascos invertidos, incapazes de reassumir a posição natural, não são na verdade uma outra forma de vida, tipo um ramo alternativo do reino animal?

Começando a ler o poema pelo fim, poderíamos dizer que, com boa dose de humor, se traça aí um paralelo algo desesperado entre a forma de vida latente no poema e o mundo animal. A poesia encarnaria uma forma de vida em extinção, que justificaria um pedido desesperado de salvação - só o outro pode reconhecer-me como sujeito como se o poema fosse uma espécie de casco a ser habitado por outros corpos ${ }^{7}$. O problema se complexifica, contudo, quando se desdobra esse reconhecimento na lógica de garantia da biodiversidade do planeta. O humor algo tenso

7 Talvez não por coincidência, é diante da pergunta a respeito de um "cágado virado" que, no início do filme Blade runner, o caçador de androides (Ridley Scott, 1982), se descobre se o entrevistado é ou não um replicante. 
talvez resida nessa ambiguidade (o desespero e o descaso, a demanda e a desfaçatez), pois, ainda que "tipo um ramo alternativo" (grifo nosso), invoca-se um sistema de classificação e repartição dos corpos pelo poder para justificar sua própria existência.

Eis uma imagem forte do jogo democrático que se formula, ainda segundo Rancière, como a parte dos que não têm parte (o "demos" na raiz de democracia), isto é, uma paradoxal forma de inclusão excludente ou exclusão inclusiva. O próprio leitor fica sem saber direito seu lugar nessa história (ou será que só o professor poderia decifrá-la?), e, no final, o poema, ou a dúvida quanto ao lugar de sua enunciação (é mesmo um poema?), resta pairando na forma de pergunta.

Há um jogo ventríloquo que remonta a certa tradição na literatura brasileira e, claro, lembra as peripécias do narrador machadiano. Ao chamar a nossa atenção 20 para a escrita, produz-se uma voz, aqui também pouco confiável, pois que desfala o que escreve e escreve algo diferente do que diz.

Para quem ocupava o posto de arte máxima até o século XVIII, é preciso admitir que alguma coisa aconteceu na política da voz encarnada na poesia. Evidente aqui uma crise de representação: é preciso justificar por que alguém pode constituir um espaço discursivo, uma voz que mereça ser ouvida ou que mereça ascender à esfera do sentido, sob pena de ficar desesperada, estrebuchando, como se também fora dessa exposição ela não existisse. Aquilo que precisa se expor para que dele tenhamos experiência, mas que perde sua própria natureza no curso dessa exposição. Entre o privado da voz e o público do poema, joga-se toda uma política da escrita, embora o próprio poema tenha de questionar o lugar que ele ocupa nessa esfera pública.

Dentro desse quadro - como na gestão de papéis sociais que confunde a política com o Estado e sua distribuição de 
cargos, verbas, bolsas -, o sujeito da política ou do poema, clamando pela sua sobrevivência como forma de defender a biodiversidade, se aproxima muito de um sujeito cínico sempre a dois passos entre o que faz e o que diz e continuamente disposto a explicar um pelo outro no sentido que tratam Sloterdijk (1987), Zizek (1992) e Safatle (2008). Ele se inclui excluindo-se e se exclui incluindo-se, está dentro e fora ao mesmo tempo, ainda que uns formulem as regras e os outros ocupem os papéis. Essa falsa consciência esclarecida, submetida a duas leis - o imperativo do gozo e da normatividade -, é capaz de produzir distorções performativas em que a contradição entre a enunciação e o enunciado se anulam sem que se produza uma contradição performativa no sentido proposto por Habermas de invalidar e desconstituir o enunciador como um agente válido na esfera argumentativa do espaço público. Essa parece ser uma estrutura bastante evidente da enunciação do poema e, em boa medida, de uma parte da poética de PHB.

Claro também que aqui é preciso pensar na complexidade da enunciação literária, embora seja importante notar uma espécie de literalização da metáfora, como se ela quase prescindisse de se desdobrar em imagem. Esse paradoxo enunciativo também não anula completamente a voz e o ritmo que pressionam a seu modo esse cinismo. Nesse ponto também, os poemas de PHB ficam criticamente no meio do caminho, "como se a vida fosse água" e escorresse pelas mãos.

\section{Até mais. Heroísmo não é a minha}

Em certo nível, a formulação cínica da enunciação perpassa todos os livros de Paulo Henriques Britto, que trazem em seu aparente formalismo uma lógica cruel do funcionamento das práticas discursivas do Brasil pós-golpe, onde se encarna no mesmo ato de fala a regra e a contravenção, a inclusão e a exclusão. Esse movimento se coloca muito 
claramente em uma série de sonetos de seu livro anterior, Trovar claro, intitulada "Até segunda ordem", onde, aparentemente, um contrabandista fala, por meio de sonetos, com seu comparsa. Os cinco sonetos têm como título a data de escrita de cada um deles.

Desde o primeiro, salta aos olhos a organização normativa da atividade e a suspensão implícita no comando de espera "até segunda ordem". Na construção ficcional da enunciação do poema, essa espera (e sua relação arbitrária com a possibilidade de um novo comando normativo que pode mudar tudo "à mercê do latejar de um músculo") é fundamental para a formulação da hesitação prolongada entre regra e quebra da normatividade com novas regras e que tem a ver com a própria estrutura rítmica dos "sonetos”. Essa expectativa também é responsável por apontar a promiscuidade discursiva, a tensão entre a voz e a escrita, e mesmo para a estrutura narrativa. Tudo se passa na imi-

22 nência de um desvelamento, com a barra pesando cada vez mais até o último dos poemas (Britto, 1997, p. 43):

\section{(19 de janeiro)}

Até esta chegar às suas mãos

eu já devo ter cruzado a fronteira.

Entregue por favor aos meus irmãos

os livros da segunda prateleira,

e àquela moça - a dos "quatorze dígitos" -

o embrulho que ficou com o teu amigo.

\footnotetext{
8 Augusto Massi já havia apontado para esse funcionamento na orelha de Trovar claro: “O tom geral é quebrado somente por 'Até segunda ordem': mantida a fachada métrica do conjunto, sentimos que foram arrancadas as tábuas que compõem o solo estrutural da narrativa. No limiar da ficção, camadas cifradas de fala deixam entrever o esgarçamento e a promiscuidade da sociedade brasileira: deputado, padre, doutor, policial”.
} 
Eu lavei com cuidado o disco rígido.

Os disquetes back-up estão comigo.

Até mais. Heroísmo não é a minha.

A barra pesou. Desculpe o mau jeito.

Levei tudo que coube na viatura,

mas deixei um revólver na cozinha, com uma bala. Destrua este soneto imediatamente após a leitura.

Num país em que a sobrevivência cotidiana está permeada de contravenções e em que até há pouco tempo qualquer forma de resistência à ditadura jogava para ilegalidade seus cidadãos, chama a atenção o modo como a regulação normativa externa se interioriza como contraste entre forma e conteúdo, tornando a regra do soneto uma forma de exclusão da fala do contrabandista, produzindo uma distorção performativa, o que revela também o modo como a própria formulação da regra enquanto retórica refinada traz no seu bojo algo da ilegalidade do contrabandista ${ }^{9}$. Exclui incluindo a fala do contrabandista ao mesmo tempo que inclui a subversão da lei como parte de sua constituição. Ou ainda, cria o imaginário de um exímio sonetista contrabandista, o que não deixa de ser uma leitura do poema.

A figura do contrabandista também não é má como figura do poeta, entre as tantas figuras pós-albatroz que PHB traz para os poemas. Mas um contrabandista nas bordas da lei ou demandando um reconhecimento pelo sistema legal, via soneto, que funciona como disfarce ou código a ser criptografado. No caso da literatura, no entanto, a alfândega é o campo literário.

9 Isso também acontece com o ritmo, questão abordada na seção "Não, essa voz não é tua" deste artigo. 


\section{Biodiversidade literária}

Como se pode ver na segunda estrofe de "Biodiversidade", o poema se constrói em torno da possibilidade escancarada de leitura por um professor ou crítico que, mais do que ler, procuraria decifrar o poema. Aqui também o seu papel é esdrúxulo como o ridículo do escrever - o uso de proparoxítonas também parece calculado -, mas instaura um horizonte de expectativas que corrobora em muito a estratégia enunciativa agora girando em torno de um campo literário que é internalizado no poema, como parte de sua efetiva condição de enunciação e como ficcionalização paródica de seu funcionamento.

Se atentarmos para a enunciação do livro Macau, veremos a marca de uma grande editora, o papel brilhante, a gramatura alta, a referência ao trabalho de professor e tradutor, em suma, a função-autor colocada em funcionamento por alguém que ocupa de forma legítima todas as 24 posições do campo, e que, no entanto, subsume essa posição autoral (a encenação do próprio campo como dissemos) em um enunciado intencionalmente pouco sofisticado (o mero desejo de aparecer), que se desdobra também em uma fala desleixada no corpo de um verso em forma aparentemente fixa, instaurando uma enunciação cínica. Ficamos entre todas as esferas de legitimação do livro, a aparência de um acabamento formal e uma fala que se diz tão desolada, como alguém que se envergonhasse do móvel narcísico de sua exposição.

Essa encenação do campo traz em seu bojo uma transformação dos modos de controle do discurso que se deu com a abertura democrática. O Brasil sai do golpe militar com um campo literário fortemente estabelecido. Isso acarreta um sem-número de instâncias mediadoras da produção, circulação e recepção, que vão desde a universidade até as formas de financiamento público, apoio, patrocínio, prêmios, bolsas, editoras, jornais etc. Essas instâncias acabam 
funcionando como uma nova forma de polícia (nos termos de Rancière), atada à formação de um campo literário relativamente autônomo (não sonhamos durante todo o século XX com ele?) e seus modos de controle a partir de posições que se ocupam no seu interior.

Todos esses fatores, desde a política até o campo literário, e mesmo as dificuldades de formalização dessa matéria complexa, tornam predominante aquilo que Rancière chama de formação de consenso, isto é,

[... a tese de que a antiga forma da política, a do conflito, caducou. A forma moderna é a do concerto, para lidar, entre parceiros responsáveis, com os dados objetivos que se impõem a todos. Segundo essa interpretação, as perturbações das democracias e as catástrofes totalitárias resultaram do fato de que os problemas reais da sociedade eram recobertos pelo jogo de sujeitos fictícios e por seus combates de fantasmas. Seres abstratos fantasmáticos classes, povo, proletariado, luta de classes - impediam a identificação dos atores reais e dos problemas objetivos da situação. O consenso é a objetivação total dos dados presentes e dos papéis a distribuir (Rancière, 2006, p. 379).

Nesse sentido, é sintomático que o último grande debate no campo da literatura, com peso para deslocar seu modo de funcionamento, tenha sido no final dos anos de 1980, e que, desde então, segundo Heloísa Buarque de Holanda no seu Esses poetas - uma antologia dos anos de 1990 -, "as palavras de ordem agora são negociação, articulação”. Tudo se passa como se a natureza do literário ou do poético, assim como o evidente desdobramento econômico de toda questão democrática tivessem se naturalizado a tal ponto que toda forma de dissenso soasse como mera inadequação. Claro que, à medida que sai de cena, o dissenso como possibilidade de rediscutir os pressupostos e o próprio "conflito 
sobre a constituição mesma do mundo comum", a teoria literária também perde a razão de existir.

Um soneto de abertura do livro Tarde, publicado após Macau ter recebido vários prêmios, evidencia como a encenação do campo torna-se parte constitutiva da forma nos poemas de Paulo Henriques Britto (2007, p. 9):

\section{Op. cit., pp. 164-165}

"No poema moderno, é sempre nítida uma tensão entre a necessidade de exprimir-se uma subjetividade ${ }^{\mathrm{TM}}$ numa personalíssima voz lírica e, de outro lado, a consciência crítica de um sujeito que se inventa e evade, ao mesmo tempo ressaltando o que há de falso em si próprio - uma postura cínica,

talvez, porém honesta, pois de boafé o autor desconstrói seu artifício, desmistifica-se para o 'leitor-

irmão..."” Hm. Pode ser. Mas o Pessoa, em doze heptassílabos, já disse o mesmo - não, disse mais - muito melhor.

Um poema como esse só é possível em um contexto no qual não há mais nada a revelar, nenhum sentido oculto, a própria decifração é parte da encenação e, no final das contas, tudo já está dado nesse jogo de cartas marcadas da crítica. Isso permite passear pelos papéis do campo, formatar em um soneto um texto crítico, ou traduzir seus próprios poemas, ou ainda fazer crítica em outros; essa encenação também desdobra continuamente a anulação recíproca entre enunciação e 
enunciado, regra de composição e a fala que enuncia, sobrepondo ritmos e desfazendo formas fechadas da tradição.

Do mesmo modo que em "Biodiversidade", a construção se dá, por um lado, como se o enunciado fizesse troça da própria enunciação - os poemas são muito construídos, mas, no fundo, são ridículos, são só uma forma de querer aparecer -; por outro lado, também a enunciação anula esse enunciado, tanto pela legitimação do livro quanto pelo poema que estamos lendo, cuja forma, de fato, revela um interesse insuspeitado.

\section{No cais úmido e ínfimo do eu}

Neste ponto, voltemos ao "Biodiversidade". Podemos dizer que o começo do poema bascula entre o eu ideal e o ideal de eu, entre a democracia performativa e a representativa, entre o "eu" que quer ser amado pelo que é ou ter de se transformar em um ideal para ser amado, entre bastar ser para ser reconhecido ou defender todo o processo de mediação da política e da arte. O que se coloca mais seriamente em jogo aqui é, no contexto em que vivemos, o lugar do eu na esfera pública, ao mesmo tempo que se torna impossível acreditar minimamente nessa encenação ${ }^{10}$.

Mas ainda assim, veja-se que se trata de uma poética do "eu", posto aqui como parte do enunciado a se chocar com a estratégia de enunciação, o tempo todo reclamando da pena desse "eu" não poder existir de verdade, nem ter de fato sumido com a pós-modernidade, a sociedade de massas, a globalização. O fato é que, no turbilhão dessas experiências, há a "quitinete do eu", de um sujeito que não consegue sair de sua esfera de dominação, quase como se o ego, e não isso nem o supereu, fossem o maior drama.

\footnotetext{
${ }^{10}$ Essa necessidade de consenso e a manutenção de estruturas imaginárias básicas comuns é expressamente defendida por Britto (2001) no artigo sobre tradução "Desconstruir para quê?".
} 
Esse território que dá título ao livro - Macau -, primeiro entreposto europeu na Ásia, traz muito do assunto do livro: lugar que até há pouco ainda se falava português, lugar não lugar, espécie de cisto rodeado de mares, outras culturas, outras línguas, às quais ele também resiste, da mesma forma que a poesia, como uma espécie de sobrevivente.

Esse lugar em torno do qual se constrói toda uma estratégia de enunciação: um eu que pode falar do eu enquanto objeto, um "eu" que se torna uma terceira pessoa, desarticulado de mim mesmo também como uma parte de mim fora de si, como um enxerto, incluído no exterior ou excluído no interior, um cisto - Macau, a quitinete do "eu" forjada no seio do ego, na sua multiplicação incessante como que a evitar qualquer deslocamento do seu lugar, ainda que mínimo, um lugar garantido das forças de fora ou das pressões do inconsciente. Como uma forma de totalizar a experiência dentro de papéis já dados e encenados, parecida com aquilo 28 que descrevemos sobre a democracia, como algo que totaliza a experiência reduzindo as possibilidades de conflito.

Talvez aí resida a grande metáfora entre o papel do "eu" e o rigor da regra formal de composição ("o múnus público da coisa" [Britto, 2003, p. 14]), como duas esferas que se colocam lado a lado sem que uma possa determinar a outra, ou entrar em um jogo de retroalimentação. É o pensamento da enunciação correndo em paralelo com a forma do poema, enquanto os enunciados por todo o livro ficam a justificar essa distorção:

\section{Há uma saída - falar, falar muito $(18)^{11}$}

Em torno da mesma toalha

A discutir a difícil questão

\footnotetext{
${ }^{11}$ Os números entre parênteses referem-se às páginas de trechos variados de poemas de Britto (2003).
} 
Porque todo argumento sempre encalha

Quando se tenta explicar a certeza

Que inspira o que dispensa explicação (41)

A compulsão sem culpa

De dar sentido a tudo (13)

Naturalmente sei que isso é banal,

E que o sabê-lo é mais banal ainda.

Melhor seria simplesmente ser, sem preocupar-se

Em ser original. Porém esse desejo

É a própria quintessência da banalidade;

E a consciência disso então... (57)

Nessa espiral infinita de explicação da explicação, justificativa contínua entre o eu e seu papel público, de uma enunciação que tem sempre o "eu" como objeto e em que a própria estrutura sutura com explicações a possibilidade de qualquer dinâmica de ressignificação, e que se contrai como coisa "sólida, consistente/ artificial" (Britto, 2003, p. 17), para se soltar como "um balão" ou "um míssil" (veja-se que são outras formas de próteses/bolsões), e que ficam ali no limbo entre o reconhecimento e a indiferença, sem que possamos saber a que se refere o "é claro que é difícil" que termina esse poema: se à utilização das regras ou se à posição subjetiva que elas colocam em jogo.

Esses finais, que se repetem por todo Macau, apontam para o fato de que nada é mais complexo nesse jogo do que terminar o poema, o que se torna a parte mais frágil dessa poética de refrações, dissonâncias que beiram a banalidade do banal: as coisas param (andam), "mesmo sem assunto", "E agora basta", "e depois nada". 
Claro também que, como já explicitou Giorgio Agamben, na medida em que o poema vive da tensão entre duas séries (semiótica e semântica) que, na modernidade, não se encontram, terminar o poema é sempre um problema, mas aqui chama a atenção o fechamento que se traduz em uma espécie de tangente vazia, como exposição da neutralização em que giram a enunciação e o enunciado. "Mais dura a delícia que sabe/ sua própria anulação" (Britto, 2007, p. 60).

A experiência do poema se aproxima aqui dos paradoxos da experiência da democracia como luta pela partilha do sensível, pela distribuição dos corpos, pela formação de dissenso sobre o que é real. O fosso que se cria entre a fantasia que sustenta o sistema e sua regulação meramente burocrática gera uma tematização contínua da distância que separa seus pressupostos e sua realização. Afinal, a Constituição cidadã e seus avanços não podem ser negados, nem a expe30 riência do poema. Essa tematização contínua da defasagem que separa o sujeito da norma ou da justificação democrática que fundamenta a própria Constituição transforma o espaço da lei em uma espécie de foro no qual não cabe o sujeito senão agentes e subordinados, operadores enfim.

Embora estejamos em um funcionamento democrático, trata-se aqui de uma relação com a lei que não implica sua internalização, mas uma inclusão excluindo, produzindo uma distância que permite encená-la, e entre a ausência de internalização e a encenação abre-se um eixo infinito de explicações racionais para a própria consciência da defasagem que essa racionalidade produz.

Esse jogo potente de remissões aproxima-se do modo pelo qual a ideia de transição encarna um jogo político em que estruturas foram mantidas atreladas a formas legais e mesmo a um excessivo legalismo que rege os corpos como sujeitos de direitos e os configura por essa demanda. Essa simulação opera por um tipo de relação com a regra, não 
mais como oposição corporal, separando corpo e linguagem, consciente e inconsciente, mas um modo pelo qual a linguagem é internalizada como espécie de ilha no ego (o fechamento da forma), Macau - desdobrando a consciência na consciência que produz um falso inconsciente, o qual, nos poemas, se mostra por esse mecanismo infinito de explicações e justificações.

\section{Não, essa voz não é tua}

O que se processa aqui, se estivermos certos, é todo um novo modo de se lidar com a lei enquanto regra no interior do poema, dentro do paradigma do consenso que configura boa parte da nossa experiência democrática. O campo literário vira palco no qual se articula o poema e que o poema mesmo encena ${ }^{12}$ e se explicita todo um conjunto de regras: os poemas são nomeados sonetos, tercinas, quadras, bagatelas, e a própria transgressão dessas formas também é nomeada. No entanto, não é possível identificar-se com a forma nem sair dela. É quase a dor da ausência de sintoma, do convívio com próteses ou como se a própria consciência tivesse se tornado uma cripta, prótese que vive da explicação da regra e de sua impossibilidade de efetivação.

Mesmo a aparência anárquica dos versos em "Biodiversidade" se dá por não ser possível reduzi-los a uma escansão silábica, na verdade, independentemente do número de sílabas (que giram entre doze, treze e catorze), a maioria deles pode ser divida em dois versos de seis sílabas, o que garante uma tensão entre a regra e uma organização muito própria do ritmo. Esse jogo entre a fala e o número (quase como se o segredo desses poemas fosse a necessidade de lê-los em voz alta) permite estar ao mesmo tempo na regra e fora dela.

\footnotetext{
12 Isso se encena mais claramente no livro seguinte, Tarde, com o poema "Op. cit. pp. 164-165". E cá não estou eu aqui o professor de literatura vexado de "ler e decifrar,/ essas palavras bestas" ("Biodiversidade", Macau).
} 
E mais, toda quebra desse jogo é semanticamente motivada: o "sou único" de fato se incrusta entre duas frases de seis sílabas; assim como "então essa fala esquisita aparentemente anárquica" e "dizendo algo mais que testando, testando, um, dois, três", produzem essa esquisitice de aparência anárquica em versos de catorze sílabas e que expõe a voz no corpo da escrita como quebra rítmica. Isso também opera no final do poema com os cascos invertidos incapazes de reassumir a posição natural, ao mesmo tempo clamando por serem vistos e destoando do todo como eventos da "biodiversidade"13.

Ao leitor, nessa estrutura argumentativa do poema, caberia colocá-los, pois, de pé, o que significa jogar o jogo dos seus paradoxos: como se todo o peso do julgamento que ninguém havia feito antes caísse sobre nós. Tipo um cara que vai ao médico para saber se está doente, numa dependência do outro para existir ou mesmo para adoecer. Esse deslocamento da voz quase que encenada no palco da 32 escritura - uma oralidade brutal que perpassa todo o livro - cria ainda mais um nível de enunciação que nos coloca entre duas lógicas que se anulam mutuamente.

É que é próprio da voz responder a duas ordens simultâneas: o corpo e a palavra, ou de modo mais explícito, a ordem do som, do sopro, do envelope sonoro, do desejo, e por outro lado sua organização em palavras, sentido. Essa voz do outro que transforma o grito puro da criança em grito para, dando ao grito uma dimensão semântica, como o clamor que percorre todo o poema, as palavras estrebuchadas como cascos pedindo o corpo da voz. Como responder ao mesmo tempo à sedução da voz e ao traço distintivo da palavra? Não seria a voz essa outra forma de vida que clama por existência no palco da biodiversidade?

Aqui talvez seja necessário retomar o que diz Rancière sobre a relação entre dissenso e voz. Para Rancière, a questão

${ }^{13}$ Com as rimas entre perfeitas, esdrúxulas e toantes acontece a mesma coisa. 
crucial do político está não no reconhecimento da voz como pura existência e que pode ser lida como ruído, som fugaz, mugido, enfim, como uma instância aquém da palavra, mas na potência de enunciação que essa voz carrega, isto é, na medida em que essa voz estabelece outro modo de relação com a palavra, o que desloca os próprios fundamentos da relação na comunidade de seres falante. $\mathrm{O}$ reverso político dessa palavra sem voz, sem corpo, órfã da democracia, é para Rancière a necessidade intrínseca que liga democracia e literatura, como se a esta coubesse dar o corpo que falta àquela.

Nesse limite entre a voz e o outro, a voz e sua articulação, joga-se o universo dessa fala esquisita, uma voz parada (que imagem para o poema!), formigando estática, no imaginário de um teste da verificação da presença do outro (a própria presença do corpo aqui está em questão), operando como função fática como se ao telefone, ao microfone, em um rádio amador. Essa voz como chamado e a iminência sempre precária do encontro.

Mas esse horizonte de possibilidade, como se apontasse para algo aquém e além do jogo de remissões, talvez resida na possibilidade de levarmos a sério a aproximação do poema com uma espécie do reino animal, isto é, como uma forma de vida. O que caberia questionar no consenso em que o poema opera é a própria partilha do que se entende por animalidade, por natureza, ou de qual mundo estamos falando quando dizemos "macau", "eu", "poema”. Mesmo a banalidade das tantas versões do mundo tornam-se risíveis na nossa cara e o relativismo é posto em xeque:

É a mais nova versão do real.

Não tão bela quanto a anterior, que no último verão fez furor e não deixou vestígio. É natural. ${ }^{14}$

14 "Três sonetos grotescos", V (Tarde). 
O problema que se coloca aí talvez não seja o de admitir muitas versões para o mesmo mundo, mas de discutir a própria existência desses mundos. O que permitiria afirmar que o problema não está nas versões nem na voz ou no reconhecimento de uma dissonância entre o que se fala e o que se faz: o problema central talvez não esteja na fala, mas na escuta, na necessidade de escutar e se fazer chamar e não de dizer. Escuta que coloca em jogo outros mundos.

É o movimento que se delineia de forma mais clara e ainda mais irônica em:

\section{História natural}

Primeira pessoa do singular:

a forma exata da sombra difusa.

Quem fala sou sempre eu a falar.

A máscara é sempre de quem a usa.

No entanto, é preciso dizer-se - mesmo

que a moda agora mande (e a moda manda, e muito) acreditar que o eu é o esmo,

o virtual, o quase extinto, o panda

desgracioso da história do Ocidente, a devorar o alimento cru que já não sabe como digerir.

Leitor amigo: para. Pensa. Sente. Conheces bem o gosto do bambu, $\mathrm{o}$ ardor nas entranhas. Tenta não rir. (Britto, 1997, p. 83)

A ironia é reveladora do descompasso, mas não deixa de ainda uma vez insinuar-se quanto o conflito dessa primeira pessoa do singular que se instaura no poema 
como um panda metafórico imposto pela moda (e o gosto compartilhado do bambu) aponta um limite indigerível, um resto não simbolizável que fica a arder (não só) nas entranhas.

Digerir, ruminar, extrair o sumo do que não tem fundo, tentar não rir do girar em falso dessa enunciação. E, como no "Biodiversidade", aqui também o panda em extinção aparece como figura do poeta (mais uma imagem pós-albatroz) como que a fazer do poema um chamado e um espaço em que só os corpos - ainda que patéticos, ou por força desse pathos - podem reinstaurar a enunciação (e de certo modo significá-la para além de suas remissões infinitas).

Se de fato tentarmos não rir ou formos a fundo no gozo desse riso, a demanda que se processa aqui, como uma voz que clama pela presença do outro (leitor amigo), atua como um movimento intrínseco às condições de possibilidade de sua própria existência. Algo da ordem de uma biodiversidade, de outros modos de articulação daquilo que chamamos vida como forma particular de encontro do corpo com outros corpos e as relações sociais que atravessam essa troca por meio da linguagem.

Com Wittgenstein, sabemos o quanto a poesia pode ser vista como uma forma de vida em um sentido muito preciso de jogo, de colocar em jogo, jogar na e com a linguagem. De modo totalmente metafórico e no limite do ridículo, o panda ruminante e os cágados estrebuchando inúteis colocam em jogo a poesia como forma de vida, como possibilidade de um campo da experiência que, sem ela, não teríamos acesso.

E chegaríamos aqui em uma posição política insuspeitada: talvez o reverso do cinismo seja a possibilidade de multiplicação da própria possibilidade: poetas, críticos, pandas, cágados, poemas. O cinismo é uma solução fácil para essa percepção do limite do humano, da literatura, do direito, da política. 
O cinismo caminha sobre os escombros de todas essas instituições (homem, literatura, direito, política), mas as mantêm intactas, como uma crença sob a ausência de crença que sustenta um desejo sem o qual a vida não é suportável. Nos poemas de PHB, poderíamos formular a hipótese de um gesto que evidencia esse problema, encena uma distorção cínica, mas também instaura um imaginário burlesco de formas de vida no lugar do homem, da poesia no lugar da literatura, do mundo no lugar do direito, do político no lugar da política.

A manutenção do poema e suas formas aparentemente fixas, deixam entrever esse lugar em que o "cais ínfimo do eu" cede para outra topologia na qual - como os corpos na cama - cada mundo perde seus contornos. Espécie de acalanto de corpos lidos pelos corpos (como no último poema de Macau): forma de vida que recusa toda substancialização do humano, toda prévia definição do direito, como se 36 Macau fosse também esse lugar fora dos universos predefinidos do mundo contemporâneo.

A força desses poemas reside também nessa possibilidade que abrem de entender algumas dinâmicas que atravessam a política, a poesia e a subjetividade. Fazem mesmo sonhar com uma esfera do político - e não da repartição política - onde os corpos produziriam a partilha do sensível como forma de dissenso, como quer Rancière. Dissenso até mesmo quanto às regras do jogo. Para parar com Rancière (2006, p. 374): "um conflito sobre a constituição mesma do mundo comum, sobre o que nele se vê e se ouve [...] não pode ser a confrontação de parceiros já constituídos sobre a aplicação de uma regra geral a um caso particular", mas obrigar a criação de outros contextos, produzir formas de dissenso, de invenção conflitual: o sujeito político como uma potência de enunciação para produzir mundos que ainda não existem. 


\section{Roberto Zular}

é professor doutor de Teoria Literária e Literatura Comparada na Universidade de São Paulo (USP).

\section{Bibliografia}

BRITTO, P. H. 1997. Trovar claro. São Paulo: Companhia das Letras. . 2001. "Desconstruir para quê?". Cadernos de Tradução, Universidade

Federal de Santa Catarina, v. 2, n. 8. Disponível em: <https://

periodicos.ufsc.br/index.php/traducao/article/view/5883/5563>.

Acesso em: 20 ago. 2015.

2003. Macau. São Paulo: Companhia das Letras.

. 2007. Tarde. São Paulo: Companhia das Letras.

BUARQUE DE HOLANDA, H. (org.). 1998. Esses poetas. Rio de Janeiro:

Aeroplano.

OLIVEIRA, F. de; RIZEK, C. S. (orgs.). 2007. A era da indeterminação. São

Paulo: Boitempo (Coleção Estado de Sítio).

PEREIRA, A. 2010. Ditadura e repressão: o autoritarismo e o Estado de

direito no Brasil, no Chile e na Argentina. São Paulo: Paz e Terra.

RANCIÈRE, J. 2006. "O dissenso”. In: NOVAIS, A. (org.). A crise da razão.

São Paulo: Cia. das letras.

SAFATLE, W. 2008. Cinismo ou falência da crítica. São Paulo: Boitempo.

SLOTERDIJK, P. 1987. Critique of cynical reason. Minneapolis: UMP.

ZIZEK, S. 1992. Eles não sabem o que fazem. O sublime objeto da ideologia.

Rio de Janeiro: Zahar. 


\section{ENCAROÇADA DE ESTRELAS: ALGUNS POEMAS DE PAULO HENRIQUES BRITTO E A TRANSIÇÃO DEMOCRÁTICA}

ROBERTO ZULAR

Resumo: Este ensaio visa articular a poética de Paulo Henriques Britto com algumas questões que emergiram no bojo da transição democrática no Brasil.

Palavras-chave: Paulo Henriques Britto; Poesia; Transição Democrática.

\section{SOME POEMS BY PAULO HENRIQUES BRITTO AND THE DEMOCRATIC TRANSITION}

Abstract: This essay aims to articulate the poetics of Paulo Henriques Britto with some issues that emerged from the democratic transition in Brazil.

Keywords: Paulo Henriques Britto; Poetry; Democratic Transition. Recebido: 02/03/2015 Aprovado: 01/08/2015 